bandage underlying it, transversely under the waist of the trowsers; and over all a thick layer of wadding is laid. On to the splint thus formed the patient is lowered in such a position that the margin of the fork of the trowsers corresponds to a point two inches and a half above the arms, and that his legs, being immediately over each leg of the trowsers, are about six inches apart at the knees. The fractured limb is held in good position by the surgeon, while two assistants, by tying together the tails of the bandage, bring the splint into close apposition with the posterior surface of the patient's legs, buttocks, and loins, and make the binder encircle the hips and abdomen. As soon as the plaster has set, the poles are passed through the folds in the canvas and the patient is removed. The whole dressing, not including the treatment of the wound and the setting of the plaster, can be applied in less than a quarter of an hour by a surgeon and two skilled orderlies. During the subsequent treatment of the case the canvas of the stretcher is never removed from underneath the patient. When an action of his bowels is about to occur, the poles are put in position, the halves of the canvas are separated, the patient is raised, and a bed-pan passed underneath him. He is lifted in a similar way when his wound requires to be dressed. The situation of this may require that windows be made in the splint and canvas: and in cases where it is apparent that this will have to be done, honp-iron, if obtainable, should be placed between the trowsers, when first put in position, so as to strengthen the splint under the injured limb.

I regret that (unforeseen circumstances preventing $\mathrm{my}$ being present at the Congress) I am unable to show by demonstration how rapidly this splint can be applied and what excellent support it affords. I have not brought it to notice without having first thoroughly tested it by having had it tried on myself in person, and I would strongly urge anyone who may think of using it to do the same. Whoever does so will, I believe, be led to agree in this that, wherever reliable plaster-of-Paris can be obtained, this method of applying it will give very great help in the treatment of a class of wounds than which no others baffle more the skill of military surgeons. Uf course the liability of plaster-of-Paris to deteriorate is a great drawback to its use on active service, and it should therefore be tested immediately before being employed. There are also, I know, other objections to its use as a material for splints, but these have force chiefly when it is used so as to surround a limb, and not when it is made to lie against one and take its shape. So employed, it is in my opinion the dressing most available for gunshot fracture of the lower limbs in connexion with transportation.

\section{ON FROTHLESS ALBUMEN IN CERTAIN CASES OF ALBUMINURIA.}

BY ROBERT KIRK, M.D. ED., F.F.P.S. GLASG.

IT is not a little remarkable that so striking a phenomenon as the frothing of albumen should have received no attention either from physiologists or clinical observers. The property on which it depends must be intimately connected with the purposes which proteid substances are destined to subserve in the animal system, and it varies in the degree in which it is manifested by different specimens of albumen. In the Glasgow Medical Journal for October, 1881, I pointed out the fact that in a few cases of albuminuria the albumen has altogether lost the frothing power, while in a much larger number of cases this property, although not entirely lost, is very much diminished in comparison with that of blood serum. The object of the present communication is again to call attention to these cases, but more especially to record a curious fact which I ascertained last winter-namely, that the more or less frothless forms of albumen appear to consist of a certain combination of serum-albumen and paraglobulin, and that when the latter is precipitated by dialysis or by saturation with salt the power of frothing is again perfectly restored to the albumen.

I first observed this with a watery extract of ox heart, which I had prepared for quite a different purpose. The solution was red, apparently containing a considerable amount of hæmoglobin, and I found on blowing a current of air through it that it was as frothless as water, not a single bubble rising to the surface. Some of it was thrown on a dialyser, and after twenty-four or more hours' dialysis
I found, to my great surprise (for the experiment was tried accidentally so to speak), that it now frothed as perfectly as. any specimen of serum albumen $I$ had ever seen. There was a large precipitate of paraglobulin, and the mixture had become very viscid and proved difficult to filter. I at once tried the same experiment with a specimen of ropy albumen from an ovarian cyst and with a comparatively frothless albumen from a case of albuminuria, and in both with an identical result. It was even more decided when the paraglobulin was thrown down by neutralising the urine, saturating with magnesium sulphate, and keeping it for twelve hours or longer in a hot-air chamber at a temperature of $100^{\circ} \mathrm{F}$. Indeed, merely stirring in a handful of salt was sufficient to produce an immediate and marked effect.

The explanation of this fact is not apparent. ' In $\mathrm{my}$ earlier experiments $I$ had found that the paraglobulin of blood serum frothed nearly quite as well as the albumen, and the serum itself, containing both together, is, as every one knows, highly frothy. I had ascertained also that. neither acid nor alkali had any considerable effect on the frothing power, and that neither saturation with salt, nor the removal of salt by dialysis, could destroy it when present. I had not, however, as now, tried the latter two procedures on the frothless forms of albumen, not having. the slightest reason to suppose they would exercise any effect on them.

Albumen as it occurs in various exudations has often much less power of frothing than blood serum. I have seen a case of hydrocele serum (second tapping) in which. the albumen was as frothless as water. In albuminuria, as far as my observations have gone, $I$ have found that the frothless forms occur in acute nephritis, and generally in the absence of confirmed and chronic renal disease. In any case of albuminuria I invariably regard a deficiency of the frothing power as in itself a very favourable symptom - an opinion which I was led to express in 1881 in the paper above referred to. A case. is there mentioned of a patient seventy-five years of age who recovered from severe albuminuria with uræmic symptoms, and enjoyed good health for several years afterwards, and whose urine throughout was nearly frotbless. At present I have under treatment a woman of fifty-five years of age who is recovering from dropsy and albuminuria of three months' duration, and complicated with pleurisy, whose urine also, though highly albuminous, has always been less frothy than serum albumen. The experiment of precipitating the paraglobulin has been frequently tried in her case, and has never failed to restore the frothing in a wonderful manner.

To form an idea of the frothing of the urine, it is not sufficient merely to shake it up in a bottle. I have sometimes employed a U-shaped tube, through which air is drawn by an aspirator; but this is too troublesome for ordinary use. It answers tolerably well to put an ounce or two of the urine into a cylindrical jar fifteen or eighteen inches high and about two or three inches in diameter, and to blow a current of air through it by means of a long glass tube conveniently bent. A hand-bellows may be used, but the expired breath answers well, a full expiration giving a tolerably uniform quantity of air in each experiment. In this manner the difference between water, normal urine, various specimens of albuminous urine, and blood serum may be readily demonstrated.

Partick, Glasgow.

\section{ON A NEW METHOD OF TREATING THE VOMITING OF PREGNANCY.}

BY WILLIAM DUNCAN, M.D., F.R.C.S,

ASSISTANT OBSTETRIC PHYSICLAN TO THE MIDDLESEX HOSPITAL.

THe complete and rapid relief which followed the local application of cocaine in the three cases here briefly recorded seems worthy of note:-

CASE 1.-Mrs. W-_, aged nineteen (hospital patient), applied on March 11th, saying she "had not been able to keep anything down for the last month." The patient looked emaciated and ill; she was just two months pregnant with her first child. On examination, the uterus was found to be markedly anteflexed, and decidedly tender when pressure was made on the cervix. Sims' speculum was introduced, and the whole of the vaginal roof and cerris 